\title{
The Physicochemical and Hydrodynamic Characteristics of the Desert Sands of Algeria to be Used in Water Treatment
}

\section{Kendouci MA ${ }^{1,2^{*}}$, Kharroubi $\mathbf{B}^{1}$, Mebarki $\mathbf{S}^{1,2}$ and Bendida $\mathbf{A}^{1,2}$}

${ }^{1}$ Department of Hydraulic, University of Science and Technology, Oran-Mohamed Boudiaf B.P. 1505 El-M'Naouer 31000 Oran, Algeria

${ }^{2}$ Department of Civil Engineering and Hydraulic, University of Bechar, Algeria

"Corresponding author: Kendouci MA, Department of Hydraulic, University of Science and Technology, Oran-Mohamed Boudiaf B.P. 1505 El-M'Naouer 31000 Oran, Algeria, Tel: +213790594126; E-mail: aminekendouci@gmail.com

Rec date: Apr 12, 2016; Acc date: May 13, 2016; Pub date: May 20, 2016

Copyright: (c) 2016 Kendouci MA, et al. This is an open-access article distributed under the terms of the Creative Commons Attribution License, which permits unrestricted use, distribution, and reproduction in any medium, provided the original author and source are credited.

\begin{abstract}
In the Sahara sand dunes extend over large areas and seem to be an obstacle in the infrastructure of the urban development of the Sahara and an ecological barrier called desertification. We are interested in the sand filtration technique, as an essential phase for the water pretreatment, such processes are recognized as well-suited to rural areas, since they have a good quality treatment, a simple and relatively low maintenance operation. Knowing that the region of Bechar (1000 km from the capital) is a sandy area, preliminary work as the sand of Beni Abbes was taken as the filter bed. The goal is the development of this material abandonment in our region.

It follows from the work at the laboratory scale, the studied sand has favorable characteristics for their use as filter bed, we can say that it is a fine sandy soil textures of an effective diameter (d10) of $0.17 \mathrm{~mm}$ and a uniformity coefficient $(\mathrm{Cu})$ of 1.76 , as well as their very low permeability of the sand which is in the range of $7.26 \times 10^{-4} \mathrm{~ms}^{-1}$.

Chemical analysis carried out on the overall fraction sand us to provide qualitative and quantitative information on the chemical composition of the sample. The results obtained indicate that the sand sample contains no manganese, the presence of aluminum and calcium iron oxide may be an indicator of the presence of these elements in different forms. Calcium oxide has important levels reached $1.15 \%$ and very probably due to the presence of calcite $\left(\mathrm{CaCO}_{3}\right)$, quartz is the most represented mineral considered insoluble portion $97 \%$.
\end{abstract}

Keywords: Algerian desert; Sand dunes; Physicochemical; Flow; Hydrodynamics; Filtration

\section{Introduction}

The Great Erg Occidental is in the northwest of the Sahara $600 \mathrm{~km}$ as the crow flies south of the Mediterranean, along $500 \mathrm{~km}$ WSW of the wide ENE $150200 \mathrm{~km}$ and covers nearly 100,000 $\mathrm{km}^{2}$ [1]. Mineralogical and particle size studies of these soft sediments to select sandy sites economic interest.

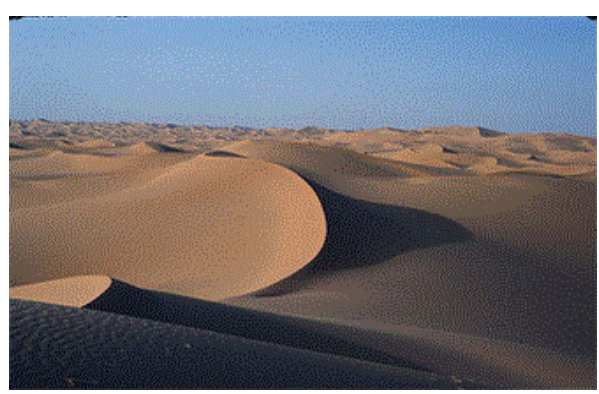

Figure 1: Great Western Erg.

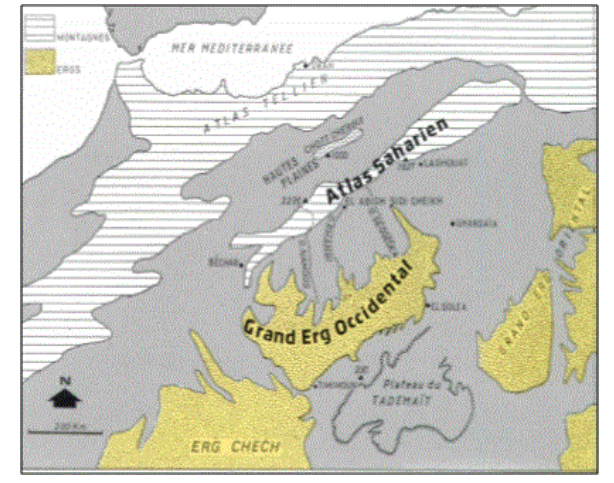

Figure 2: Localization of the Western Erg.

These stretches of sand known as Ergs to give a landscape that characterizes the Sahara and giving it a particular site, and to value this type of unique landscape, the media coverage of these sites is a great contribution to the economy of the region (Figures 1 and 2)[2].

In the Sahara sand dunes extend over large areas and seem to be an obstacle in the infrastructure of the urban development of the Sahara and an ecological barrier called desertification. The study of this sandy site also presents a cartographic impact, so the exploration of the substratum is difficult to explore. 
Citation: Kendouci MA, Kharroubi B, Mebarki S, Bendida A (2016) The Physicochemical and Hydrodynamic Characteristics of the Desert Sands of Algeria to be Used in Water Treatment. Hydrol Current Res 7: 243. doi:10.4172/2157-7587.1000243

Page 2 of 4

Ergs hide bodies of water, oil tanks, gas and even house extensions high economic interest, thus mapping and sampling hidden by sand samples give additional geo-economic data. The study of its tracts is to support scientifically to identify the economic potential that these sites can offer sand and hide [2].

\section{Location of the studied sand dune}

The oasis Beni Abbes claimed capital of Saura is found at about 1200 $\mathrm{km}$ from the capital Algiers. It is located $250 \mathrm{~km}$ south from the capital Bechar (e.g., Department of Saura). This oasis is limited to the south by Merhouma area, to the west by the plateau of the Hamada Guir, east and north by a spectacular system of sand dunes of the Grand Erg Occidental (Figure 3).

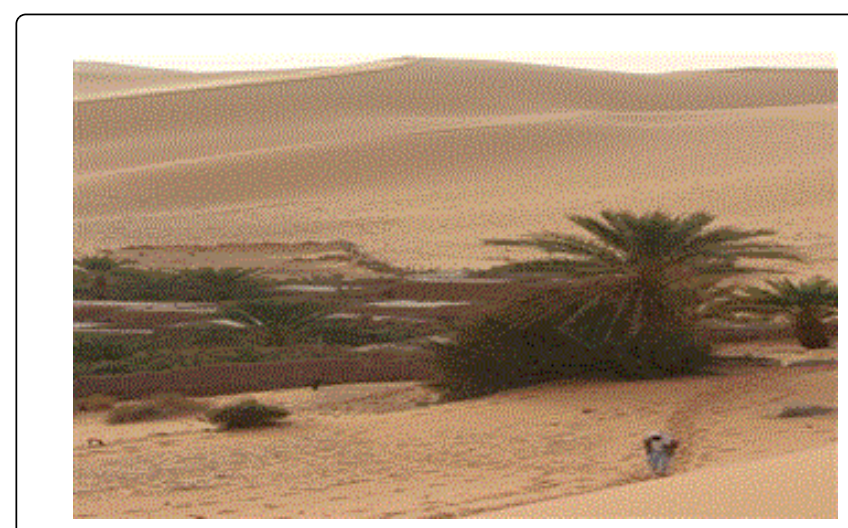

Figure 3: Sand dunes in the region of Beni Abbes.

\section{Materials and Methods}

\section{Chemical analysis}

The dosing: $\mathrm{SiO}_{2}, \mathrm{Al}_{2} \mathrm{O}_{3}, \mathrm{SO}_{3}, \mathrm{MgO}, \mathrm{Fe}_{2} \mathrm{O}_{3}$ made by X-ray fluorescence Ignition loss: determining the mass fraction lost by a sample during calcinations at $1100^{\circ} \mathrm{C}$. To losses at $550^{\circ} \mathrm{C}$, are added those resulting from the decomposition of various materials (including carbonates) and out of the water content of certain components such as clays when presents. This determination turns especially useful for "closing" tabulations of elementary analysis; we then consider the various elements in the form oxides.

\section{Physical analysis}

Particle size analysis: The test consists in classifying the different constituents grains the sample using a series of sieves, nested one in the other (standard method NF ISO 565), whose opening sizes are decreasing from top to bottom. The studied material is placed in the upper part of the screen and grains rankings are obtained by vibration of the sieve stack. The amount of accumulated refusal measured on different screens and the undersize on the bottom (fillers) must coincide with the weight of the sample introduced in the column heading [2].

The density: The density of a granular material is the ratio between its mass and volume. For a given aggregate, this report is a constant that is specific to the physical characteristics of the aggregate. She can characterize an aggregate and link its mass and volume. The bulk density of the granules is the ratio between the mass of the aggregate and the apparent volume of the aggregate. Absolute density of the aggregate is the ratio of the mass of the aggregate and the absolute volume of the aggregate.

Porosity: This is the percentage of the total volume of open voids to the apparent volume of the material of the sample [2].

\section{Experimental device}

The Figure 4 shows the experimental device used for performing the filtration tests. The driver consists of a glass column of $5 \mathrm{~cm}$ diameter and $100 \mathrm{~cm}$ in height and cylindrical. The effective height of the filter bed and $60 \mathrm{~cm}, 30 \mathrm{~cm}$ is used for filtered water that is kept constant throughout the experiment, to keep the same hydraulic load on the filter bed of sand [3].

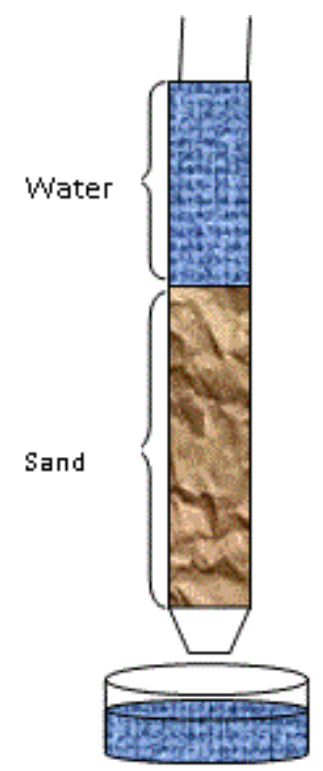

Figure 4: Schematic showing the experimental device.

\section{Results and Discussion}

The grading curve of the sand has been drawn up by passages on sieve columns (Standardized method NF ISO 565) (Figure 5).

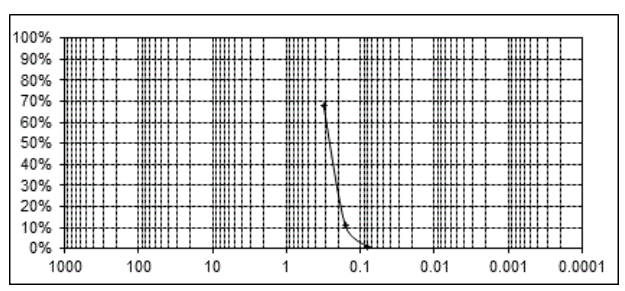

Figure 5: Granulometric curve of the sand.

The type of sand studied belongs to the fine sand category. This is confirmed by its low porosity $42 \%$; close to those found in the literature, the usual values of porosity for soils range between $30-60 \%$, which more or less fine sand can also be quantified by the effective diameter $\mathrm{d} 10$ estimated from particle size analysis which is of the order 
of $0.17 \mathrm{~mm}$, the fineness modulus (FM) 2.16 for sand; and their very low permeability of the sand which is on the order of $7.26 \times 10^{-4} \mathrm{~ms}^{-1}$ classes according to of good permeability and as noted in Table 1 [4], the coefficient of uniformity is well below 2 it can be concluded that the sand has a uniform particle size, by convention, if $\mathrm{CU}$ is between 1 and 2, the particle size is said uniform [5].

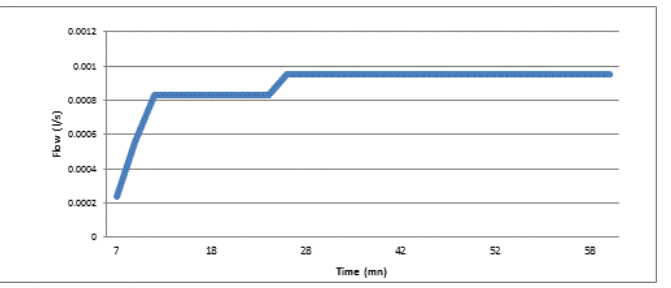

Figure 6: Evolution of sand filter flow.

The Figure 6 shows the change in the rate over time for the filter bed, the results are obtained for equal water depth is $30 \mathrm{~cm}$, according to the hydrodynamic study of the porous medium we got a rate of 0.95 $\times 10^{-6} \mathrm{~m}^{3} / \mathrm{s}$ and permeability was recorded which is of the order of 7.26 $\times 10^{-4} \mathrm{~m} / \mathrm{s}$, it is justified as it has been noted in Table 1 [6].

\begin{tabular}{|l|l|}
\hline Parameter & Sand \\
\hline Fineness modulus $(\mathrm{FM})$ & 2.16 \\
\hline Effective diameter d10 mm & 0.17 \\
\hline Coefficient of uniformity $(\mathrm{CU})$ & 1.76 \\
\hline Surface area of the material $\mathrm{cm}^{-1}(\mathrm{As})$ & 36.69 \\
\hline Permeability $(\mathrm{m} / \mathrm{s}) 10^{-4}$ & 7.26 \\
\hline Absolute density $\mathrm{kg} / \mathrm{m}^{3}$ & 2.63 \\
\hline Porosity\% & 42.01 \\
\hline pH & 7.02 \\
\hline Conductivity $(\mu \mathrm{S} / \mathrm{cm})$ & 62 \\
\hline
\end{tabular}

Table 1: The physical characteristics of the sand.

Chemical analysis carried out on the overall fraction sand us provides qualitative and quantitative information on the chemical composition of the sample (Figure 7).

The results obtained indicate that the sand sample do not contain a manganese, the presence of iron and aluminum oxides can be an indicator of the presence of these elements in different forms, goethite $\mathrm{FeO}(\mathrm{OH}) ; \mathrm{Fe}_{2} \mathrm{O}_{3}$ hematite; gibbsite $\mathrm{Al}(\mathrm{OH})_{3}$; which are recognized as mineral high reactivity and a strong power phosphorus adsorbent [7].

Calcium oxide has significant concentrations in the sand and attained $1.15 \%$ most likely due to the presence of calcite $\left(\mathrm{CaCO}_{3}\right)$ recognized as soluble and which can condition the presence of $\mathrm{Ca}^{+2}$, the present iron oxide a concentration of $0.18 \%$ [8].

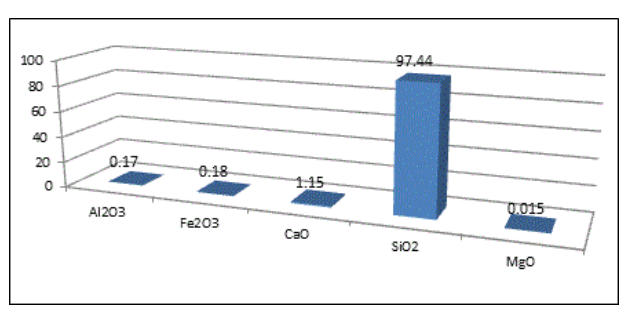

Figure 7: Chemical characterization (\%) of sand.

\section{Conclusion}

It follows from the work at the laboratory scale, the studied sand has favorable characteristics for their use as filter bed, we can say that it is a sandy soil textures end of an effective diameter (d10) of $0.17 \mathrm{~mm}$ and a uniformity coefficient $(\mathrm{Cu}) 1.76$.

The chemical analysis on the overall fraction of sand (gross) us provides qualitative and quantitative information on the chemical composition of the sample. The results obtained indicate that the sand sample contains no manganese, the presence of aluminum and calcium iron oxide may be an indicator of the presence of these elements in different forms. The oxide of calcium present in significant concentrations attained $1.15 \%$ and very probably due to the presence of calcite $\left(\mathrm{CaCO}_{3}\right)$, quartz is the most represented mineral considered the insoluble portion in the sand $97 \%$.

According to the study of the hydrodynamic filter sand bed was found a flow rate of $9.5 \times 10^{-4} \mathrm{l} / \mathrm{s}$, this flow are at least in the same range in the sand filters.

Filtration processes are widely used in various methods of treatment or pre-treatment of water for human use, agricultural and following industrial nature of the various effluents Treaty. In filtration process sand, their specified lies in the simplicity of implementation and management. The availability of the material used as filter bed (economic criterion) simplicity of implementation and management (technical criteria) are criteria that we are driven to do this study in the valued goal this material that can be exploited in regions of southwestern Algeria where he comes (sand) in sufficient quantity.

\section{Acknowledgements}

The authors would like to express their gratitude to the MESRS of Algeria for the support.

\section{References}

1. Callot Y (1991) Story of massive dunes of the Grand Erg Occidental (Algeria) Geodynamics of continental environments. Drought 2: 26-39.

2. Kendouci MA, Kharroubi B, Khelfaoui R, Bendida A, Dennai B, et al. (2013) Simulation of water filtration in porous zone based on Darcy's law. Energy Procedia 36: 163-168.

3. Kendouci MA (2012) Development of local materials for wastewater pretreatment. Master Thesis, University of Bechar, Algeria.

4. Lenoble V (2003) Removal of Arsenic for the production of drinking water: chemical oxidation and adsorption on innovative solid substrates. University of Limoges.

5. Gaillard B (1994) The methods of tracing for the study of groundwater flow. Master Course Hydrogeology, Grenoble University. 
Citation: Kendouci MA, Kharroubi B, Mebarki S, Bendida A (2016) The Physicochemical and Hydrodynamic Characteristics of the Desert Sands of Algeria to be Used in Water Treatment. Hydrol Current Res 7: 243. doi:10.4172/2157-7587.1000243

Page 4 of 4

6. Hamoda MF, Ghusain EL, Al-Mutairi NZ (2004) Sand filtration of wastewater for tertiary treatment and water reuse. Desalination 164: 203-211.

7. Dridi L (2003) Transferring a chlorine mixture in heterogeneous porous aquifer. PhD Thesis, University Louis Pasteur, Strasbourg.
8. Elouazzani D (2005) Characterization physicochemical and building development and construction of ashes from the incineration of paper mill sludge. PhD Thesis, Institute of Applied Sciences in Lyon. 